\title{
Satisfaction with Childbirth Services Among Ultra-Orthodox and Non-religious Mothers in Israeli Hospitals: A Comparative Study
}

\author{
Iris Gertner Moryossef ${ }^{1,}$, , Keren Or Chen ${ }^{2}$ \\ ${ }^{1}$ Management of Service Organizations, Hadassah Academic College, Jerusalem, Israel \\ ${ }^{2}$ Psychology Department, Haifa University, Haifa, Israel
}

Email address:

irisge@edu.hac.ac.il (I. G. Moryossef), korchen@psy.haifa.ac.il (K. Or Chen)

${ }^{*}$ Corresponding author

\section{To cite this article:}

Iris Gertner Moryossef, Keren Or Chen. Satisfaction with Childbirth Services Among Ultra-Orthodox and Non-religious Mothers in Israeli Hospitals: A Comparative Study. Journal of Gynecology and Obstetrics. Vol. 9, No. 2, 2021, pp. 36-41. doi: 10.11648/j.jgo.20210902.12

Received: February 18, 2021; Accepted: March 1, 2021; Published: March 9, 2021

\begin{abstract}
Introduction: A mother's satisfaction with her childbirth experience affects her sense of being a mother in the first few postpartum months. Therefore, the labor services provided by hospitals have an important role and have been the topic of numerous studies. Israel enjoys a particularly high birth rate (twice as high as in other OECD countries), with over $99 \%$ of deliveries taking place in public hospitals, making it a good case study for examining satisfaction with childbirth services. In addition, Israel has at least two distinct populations - ultra orthodox and non-religious - allowing us to examine possible differences in how the experience of hospital childbirth is perceived in different communities. The current study examines the differences, if any, between Ultra-Orthodox Jewish Mothers (UOJM) and Non-Religious Jewish Mothers (NRJM) in their satisfaction with hospital childbirth services. Aim: The study focuses on the differences between the factors that influence NRJM's and UOJM's satisfaction with childbirth services Procedure: This is a comparative study based on a sample of 232 non-religious and 161 ultra-orthodox mothers who have given birth in a public hospital in Israel. Eighteen items defining childbirth satisfaction were rated on a 5-point Likert Scale. The items have been grouped together into three dimensions: The Personal Care dimension includes the interaction of the service provider (midwife or healthcare provider) with the mother, their professionalism, empathy, attitude, responsiveness, etc.; the Surrounding Atmosphere dimension contains items related to the delivery room like its hygiene or aesthetics; and the Technical Methods dimension, which relates to the emergency and alternative care equipment. Results: The study shows that in both sectors, satisfaction was significantly influenced by the dimensions of Personal Care and Technical Methods; however, the Surrounding Atmosphere dimension influenced only ultraorthodox mothers. Conclusions: The results emphasize the importance of personal interaction with the patient, as well as the presence of appropriate technical methods in the delivery room. When a mother is satisfied with these two dimensions, she is more likely be to be satisfied with her overall birth care. Hospitals should therefore focus on the personal interaction of the staff with the mother, as well as on being service oriented and providing high quality and professional obstetric care. They should also emphasize the cleanliness of the delivery room and its general atmosphere, especially when the patient is from the ultra-orthodox community.
\end{abstract}

Keywords: Childbirth Satisfaction, Ultra-Orthodox Jewish Mother, Non-Religious Jewish Mother, Obstetric Care

\section{Introduction}

Mother's satisfaction with the experience of childbirth is known to affect their postpartum wellbeing and have thus been studied in previous research [1-3].

The correlations between patients' satisfaction and the dimensions of personal care, physical surrounding, and medical process have been demonstrated in a variety of related models. The Customer Satisfaction Questionnaire [46]. highlights the role of the service provider (doctors or physicians) and the technical process of the medical service in ensuring a patient's positive experience. 
When examining satisfaction with childbirth services, Israel provides a good testing ground. This is because ove $r$ $99 \%$ of Israeli births occur in public hospitals (due to their ability to provide advanced healthcare and the known risks of home deliveries). The Social Security grant given to hospitals for each delivery $(\$ 3,000)$, and patients' freedom to choose any hospital, have created fierce competition in this market, driving hospitals to put much effort into convincing women in labor to choose their services. These efforts include free childbirth courses, upscale delivery rooms, special meals, an option to obtain private labor-support services, alternative childbirth options, and more.

The relatively high birthrate in Israel (3.1 per woman, compared to an OECD average of 1.9), and the even higher birthrate in the ultra-orthodox community $(7.8$ children on average), have made it particularly interesting to examine the elements that play a role in mothers' satisfaction with childbirth services in Israel, and to identify ways to enhance it.

In addition to variance in birthrate, the two populations non-religious and ultra-orthodox Jewish mothers - also differ in other demographic characteristics: on average, the nonreligious mother is more educated, has a bigger income, and is older (the average age for first childbirth is 27.8 among non-religious Jewish mothers compared to 21.3 among ultraorthodox mothers) (http://taubcenter.org.il/wpcontent/files_mf/fertilityratesheb.pdf).

The ultra-orthodox Jewish community in Israel is closed and conservative; its members live in isolated groups with minimal exposure to online communication. Ultra-orthodox mothers obtain information on obstetric care mostly through word-of-mouth communication between community members; if a woman is satisfied with her childbirth experience, she will recommend the facility to her friends and family members.

In the non-religious Jewish sector too, due to the high involvement in obstetric care, a woman is likely to choose a particular facility over another because of personal recommendations and not through mainstream media. This is despite the fact that this sector, unlike the ultra-orthodox one, is an avid user of digital media in addition to word-of-mouth communication.

\section{Scope and Objectives}

The current study examines satisfaction with childbirth services among two Israeli populations: ultra-orthodox and non-religious Jewish mothers. It aims to track the similarities and differences between these two populations and possibly connect them to the distinct socio-demographic characteristics of each group. The correlation between satisfaction with services and customer loyalty has been demonstrated in healthcare services, making this research topic highly relevant in the healthcare market.

It will be interesting to examine differences between the factors that influence mothers' satisfaction with delivery services among the two sectors: UOJM and NRJM in Israel.

\section{Methodology}

\subsection{Data Collection}

The study is based on a sample of 232 non-religious Jewish mothers (NRJMs) and 161 ultra-orthodox Jewish mothers (UOJMs) who gave birth within a period of 12 months prior to the study (which was conducted in 2018). We used close-ended questionnaires based on the Donabedian quality assessment framework [7]. To measure mothers' satisfaction with their childbirth experience [3, 7, 8]. Each questionnaire contained 18 items, which were rated on a 5point Likert scale (1 - very dissatisfied, 2 - dissatisfied, 3 neutral, 4 - satisfied, and 5 - very satisfied). The items have been grouped together into three dimensions: The Personal Care dimension includes the interaction of the service providers (midwives and physicians) with the patient as well as their empathy, attitude, responsiveness, and professionalism; the Technical Methods dimension relates to the availability of alternative and emergency care equipment; and the Surrounding Atmosphere dimension contains items related to hygiene, aesthetics, and teamwork in the delivery room.

\subsection{Socio-demographic Characteristics}

We also recorded the sociodemographic variables of the sample populations, including age, income, number of pregnancies, and level of education, as describes in Table 1.

Table 1. Socio-demographic characteristics (in percentage) of NRJM and UOJM.

\begin{tabular}{|c|c|c|c|}
\hline Variables & & UOJM \% & NRJM \% \\
\hline \multirow[b]{2}{*}{ Age } & $18-27$ & 26 & 28 \\
\hline & $27-35$ & 45 & 48 \\
\hline \multirow{2}{*}{ Education } & Low level of education (high school) & 51 & 20 \\
\hline & High level of education (BA or higher) & 49 & 80 \\
\hline \multirow{3}{*}{ Primiparity } & Nulliparous (mother for the first time) & 33 & 9 \\
\hline & Parous (1-4 children at home) & 35 & 35 \\
\hline & Multiparous (has more than 4 children) & 32 & 56 \\
\hline \multirow{3}{*}{ Income } & Lower than average & 25 & 18 \\
\hline & Average & 40 & 27 \\
\hline & Higher than average & 35 & 55 \\
\hline
\end{tabular}




\section{Results}

\subsection{Dimensions Predict Mother's Satisfaction}

Linear multiple regression was conducted to identify the dimensions that predict mothers' satisfaction (Table 2). The linear regression explained $89 \%$ and $93 \%$ of the satisfaction variance $(F(3,46 ; 3.47))$ in NRJM and UOJM, respectively.

Results show that both ultra-orthodox and non-religious mothers were significantly influenced by the dimensions of Personal Care and Technical Methods. The Surrounding Atmosphere dimension had significant correlation with satisfaction only among ultra-orthodox mothers.

Table 2. Linear multiple regression of satisfaction dimensions.

\begin{tabular}{|c|c|c|c|c|c|c|c|c|}
\hline \multirow{2}{*}{ Dimension } & \multicolumn{2}{|l|}{ B } & \multicolumn{2}{|c|}{ Std. Error } & \multicolumn{2}{|l|}{ Beta } & \multicolumn{2}{|l|}{ t } \\
\hline & UOJM & NRJM & UOJM & NRJM & UOJM & NRJM & UOJM & NRJM \\
\hline Personal Care & .594 & .57 & .03 & .04 & .594 & .57 & $17.63 * *$ & $12.64 * *$ \\
\hline Technical Methods & .474 & .36 & .02 & .02 & .474 & .45 & $14.23 * *$ & $9.37 * *$ \\
\hline Surrounding Atmosphere & .437 & 0.17 & .02 & 0.1 & .437 & 0.1 & $13.36 * *$ & 1.13 \\
\hline
\end{tabular}

${ }^{*} \mathrm{p}<0.05 * * \mathrm{P}<0.01$

\subsection{Correlation with Demographic Variables}

Using Sperman test to check for correlations between the mother's satisfaction and her sociodemographic variables (Table 3) reveals significant correlations only in NRJMs. In this sector, the dimension of Personal Care was found to have a significant positive correlation with education and a significant negative correlation with age.

In other words, among the non-religious population, the younger and more educated a woman is, the more likely she is to be satisfied with her childbirth experience. In contrast, no significant correlation with demographic variables was seen among ultra-orthodox mothers.

Table 3. Sperman Correlation between dimensions of satisfaction and demographic variables.

\begin{tabular}{|c|c|c|c|c|c|c|c|c|}
\hline \multirow{2}{*}{ Dimension } & \multicolumn{2}{|l|}{ Age } & \multicolumn{2}{|c|}{ Education } & \multicolumn{2}{|l|}{ Income } & \multicolumn{2}{|c|}{ Previous childbirths } \\
\hline & UOJM & NRJM & UOJM & NRJM & UOJM & NRJM & UOJM & NRJM \\
\hline Personal Care & -.07 & $-0.24 *$ & -.05 & $0.41 * *$ & .11 & 0.12 & -.14 & -0.13 \\
\hline Technical Methods & .01 & -0.15 & -.09 & -0.11 & .07 & 0.03 & .08 & 0.06 \\
\hline Surrounding Atmosphere & -.15 & 0.02 & .19 & 0.09 & .19 & 0.06 & -.11 & -0.11 \\
\hline Age when giving birth. & -.07 & --0.09 & -.04 & $-0.24 *$ & .18 & 0.10 & -.07 & -0.07 \\
\hline
\end{tabular}

$* \mathrm{p}<0.05 * * \mathrm{P}<0.01$

As seen in Table 4, in both sectors, demographic variables (age, income, education, and previous childbirths) did not significantly predict satisfaction with obstetric care $(\beta=-.05$ in both samples).

\subsection{Significance of the Factors Predict Mother's Satisfaction}

It was found that Personal Care and Technical Methods are the main predictors of satisfaction in both sectors. In contrast,
Surrounding Atmosphere was found as a significant predictor of childbirth satisfaction only among non-religious mothers.

Using regression analysis (Table 4), Personal Care and Technical Methods are shown to be the main predictors of satisfaction among both religious and non-religious populations. Surrounding Atmosphere significantly predicted satisfaction only in the ultra-orthodox sector. Demographic variables did not predict childbirth satisfaction in either sector.

Table 4. Linear multiple regression of factors that affect mothers' satisfaction.

\begin{tabular}{|c|c|c|c|c|c|c|c|c|}
\hline \multirow{2}{*}{ Dimension } & \multicolumn{2}{|l|}{ B } & \multicolumn{2}{|c|}{ Std. Error } & \multicolumn{2}{|l|}{ Beta } & \multicolumn{2}{|l|}{ t } \\
\hline & UOJM & NRJM & UOJM & NRJM & UOJM & NRJM & UOJM & NRJM \\
\hline Personal Care & .62 & 0.62 & .02 & .004 & .47 & .48 & $23.81 * *$ & $10.46 * *$ \\
\hline Technical Methods & .37 & 0.35 & .03 & 0.03 & .27 & 0.35 & $11.78 * *$ & $8.38 * *$ \\
\hline Age when giving birth & .06 & .0 .12 & .04 & 0.01 & .05 & -0.13 & 1.42 & -1.42 \\
\hline Education & -.04 & 0.24 & .04 & 0.06 & -.05 & 0.24 & -1.09 & -1.32 \\
\hline Income & -.02 & 0.21 & .03 & 0.05 & -.02 & -0.21 & -.67 & -.67 \\
\hline
\end{tabular}

$* \mathrm{p}<0.05 * * \mathrm{P}<0.01$

\section{Conclusions}

The level of satisfaction with childbirth is known to affect women's postpartum wellbeing and have thus been studied in previous research $[1,9,10]$, The results of the current study indicate the importance of Personal Care and Technical 
Methods in influencing satisfaction among both religious and non-religious mothers. Women are more likely to be satisfied with their hospital childbirth when they have positive interactions with service providers and when there is availability of technical equipment in the room.

The significance of personal care and technical methods for both sectors can be explained because for every woman, childbirth is an important change accompanied by uncertainty, and the presence of supportive medical staff and appropriate equipment may have an important role in reassuring her. [9$11]$.

These results reinforce findings from former studies, showing the importance of both the Technical Methods (including the presence of medical personnel as well as emergency and alternative care equipment) and Personal Care. Both have been demonstrated as central components that influence women's satisfaction with their labor experience. [2, 4, 11-14].

Further, the results were similar for both UOJMs and NRJMs; both dimensions - Personal Care and Technical Methods - were identified as significant predictors of satisfaction in both populations. In other words, in both sectors, mothers look for quality personal care and advanced technical equipment. These shared needs emphasize the importance of providing excellent service by the healthcare facility, as was discussed in Donabedian's framework $[15,16]$ and d Mackey's MCSRS model [3, 5, 17-19].

Correlations between demographic variables and mother satisfaction were seen only between the Personal Care dimension and the variables of age (a negative correlation) and education (a positive correlation), in the non-religious sample only. In other words, when a non-religious mother is older and more educated, she is more likely to be satisfied with her childbirth experience. A possible explanation for these findings is that younger and less educated mothers have more doubts and uncertainty during childbirth, thus they require a stronger sense of assurance from the hospital staff and equipment.

In both sectors, no significant correlation was found between the demographic variables and the dimensions of Technical Methods and Surrounding Atmosphere. In other words, mothers are influenced by the same items - such as cleanliness, medical equipment, and teamwork - regardless of their age, income, education, former childbirths, and religious inclination.

These disparities can be explained by the differences in access to information. The non-religious woman is exposed to different kinds of media, including social networks, professional literature, and a computer, which enable her - as she becomes mature and better educated - to collect information prior to childbirth, so that she is better prepared and knows what to expect. Consequently, her satisfaction does not depend on the dimensions of Personal Care and Technical Methods. In contrast, the ultra-orthodox mother has no exposure to digital communication, thus her knowledge about childbirth and her confidence in its results are drawn from the staff and the equipment. [20-22].
Older and less educated non-religious mothers, on the other hand, may be less forgiving towards the medical staff, thus are less likely to be satisfied with it. This conclusion can find support in other studies [9, 23, 24], which have shown that older and less educated mothers are less patient with regards to childbirth and have higher expectations for staff attention, thus tend to be less satisfied with the dimension of interpersonal communication. These results contrast with other studies, which demonstrate a positive correlation between age, income, and other demographic variables and childbirth satisfaction [1, 3, 19, 25]. In our study, no significant correlation was found in either sector between any of the three dimensions and other variables (income, previous childbirths).

The main differences between NRJMs and UOJMs indicated in this study relate to the Surrounding Atmosphere dimension. This dimension contains items related to the hygiene, sanitation and cleanliness in the room. Our study shows that it significantly affected patient satisfaction, in line with the literature [22-26], but only among ultra-orthodox participants. Surprisingly, the satisfaction of non-religious mothers was not influenced by elements related to the atmosphere in the delivery room. [1, 26, 27].

Assuming that delivery rooms are similar for all birthing women, these differences may suggest that non-religious mothers ascribe less importance to the surrounding space. Its cleanliness or hygiene level is less important to them, as they are more focused on the professional background of the staff and the technical equipment. In addition, non-religious mothers are often accompanied by their husbands and/or a professional doula, who may be helpful in making the stay in the room more pleasant and perhaps even clean the room. Together with the mother, they focus on the labor and are undistracted by external elements. In the more conservative ultra-orthodox sector, however, the husband does not accompany the mother throughout the labor, and using the services of a private doula is rare, due to their high cost and the small number of ultra-orthodox doulas.

The study emphasizes the value of personal interaction with the service provider and of the technical methods of childbirth for all mothers regardless of their age, income, education, former childbirths, and especially their religiousness. It is not enough for a woman in labor to be treated by empathic, attentive, and understanding caregivers; alternative and emergency medical equipment, as well as the accessibility of the staff, also play an essential role in her satisfaction and affect her childbirth experience. As childbirth is a meaningful event in a woman's life that involves pain and anxiety, having a sense of confidence in the medical staff and the equipment is essential for a pleasant labor experience.

The contribution of this research is in showing the importance of personal care and appropriate equipment in the delivery room for all women, and confirming the importance of alternative and emergency medical equipment during the labor. In other words, the Israeli woman wishes to feel safe, not only comfortable, when giving birth. 


\section{Abbreviations}

NRJM - Non-Religious Jewish Mother

UOJM - Ultra-Orthodox Jewish Mother

\section{Consent to Publish}

The manuscript does not include any individual person's data, hence consent to publish is not applicable.

Ava

\section{Competing Interests}

The authors declare that they have no competing interests.

\section{Acknowledgements}

We would like to extend our deepest gratitude to the Hadassah Academic College.

Our appreciation goes to the data collectors and supervisors who have helped us in monitoring and supervising the data collection process. Our special thanks also go to the Heads of the Hadassah Academic College.

\section{References}

[1] Srivastava, A., Avan, B. I., Rajbangshi, P., \& Bhattacharyya, S. (2015). Determinants of women's satisfaction with maternal health care: a review of literature from developing countries. BMC pregnancy and childbirth, 15 (1), 97.

[2] Bramadat, I. J., \& Driedger, M. (1993). Satisfaction with childbirth: theories and methods of measurement. Birth, 20 (1), 22-29.

[3] Goodman, P., Mackey, M. C., \& Tavakoli, A. S. (2004). Factors related to childbirth satisfaction. Journal of advanced nursing, 46 (2), 212-219.

[4] Attkisson, C. C., \& Greenfield, T. K. (1994). Client Satisfaction Questionnaire-8 and Service Satisfaction Scale-30. Bryanton, J., Gagnon, A. J., Johnston, C., \& Hatem, M. (2008). Predictors of women's perceptions of the childbirth experience. Journal of Obstetric, Gynecologic \& Neonatal Nursing, 37 (1), 24-34.

[5] Moudi, Z., \& Tavousi, M. (2016). Evaluation of Mackey childbirth satisfaction rating scale in Iran: what are the psychometric properties? Nursing and midwifery studies, 5 (2).

[6] Goodman, Y., \& Witztum, E. (2002). Cross-cultural encounters between careproviders: Rabbis' referral letters to a psychiatric clinic in Israel. Social Science \& Medicine, 55 (8), 1309-1323.

[7] Donabedian, A. (2005). Evaluating the quality of medical care. The Milbank Quarterly, 83 (4), 691-729.

[8] Green, J. M., Coupland, V. A., \& Kitzinger, J. V. (1990). Expectations, experiences, and psychological outcomes of childbirth: a prospective study of 825 women. Birth, 17 (1), $15-24$.
[9] Ajayi, A. I. (2019). "I am alive; my baby is alive": Understanding reasons for satisfaction and dissatisfaction with maternal health care services in the context of user fee removal policy in Nigeria. Plos one, 14 (12), e0227010.

[10] Christiaens, W., Van De Velde, S., \& Bracke, P. (2011). Pregnant women's fear of childbirth in midwife-and obstetrician-led care in Belgium and the Netherlands: test of the medicalization hypothesis. Women \& health, 51 (3), 220239 .

[11] Christiaens, W., \& Bracke, P. (2007). Assessment of social psychological determinants of satisfaction with childbirth in a cross-national perspective. BMC Pregnancy and childbirth, 7 (1), 26.

[12] Johnson, A. R., Kumar G, M., Jacob, R., Jessie, M. A., Mary, F., Agrawal, T., \& Raman, V. (2019). Fear of childbirth among pregnant women availing antenatal services in a maternity hospital in rural Karnataka. Indian journal of psychological medicine, 41 (4), 318-322.

[13] Tayelgn, A., Zegeye, D. T., \& Kebede, Y. (2011). Mothers' satisfaction with referral hospital delivery service in Amhara Region, Ethiopia. BMC pregnancy and childbirth, $11(1), 78$.

[14] Tadesse, B. H., Bayou, N. B., \& Nebeb, G. T. (2017). Mothers' satisfaction with institutional delivery service in public health facilities of Omo Nada District, Jimma Zone. Clinical Medicine Research, 6 (1), 23-30.

[15] Donabedian, A. (1980). Explorations in quality assessment and monitoring definition of quality and approaches to its assessment. Ann Arbor.

[16] Donabedian, A. (1988). "The quality of care: How can it be assessed?". JAMA. $260 \quad$ (12): 1743-8. doi: 10.1001/jama.1988.03410120089033. PMID 3045356.

[17] McCleain, C. S. (1983). Perceived risk and choice of childbirth service. Social Science \& Medicine, 17 (23), 18571865 .

[18] Donabedian, A. (1997). The quality of care. How can it be assessed? Arch Pathol Lab Med, 121, 1145-1150.

[19] Melese, T., Gebrehiwot, Y., Bisetegne, D., \& Habte, D. (2014) Assessment of client satisfaction in labor and delivery services at a maternity referral hospital in Ethiopia. The Pan African medical journal, 17.

[20] Lumadi, T. G., \& Buch, E. (2011). Patients' satisfaction with midwifery services in a regional hospital and its referring clinics in the Limpopo Province of South Africa. Africa Journal of Nursing and Midwifery, 13 (2), 14-28.

[21] Lucas, A. F. (2003). The determinants and effects of slot services cape satisfaction in a Las Vegas hotel casino. UNLV Gaming Research \& Review Journal, 7 (1), 1.

[22] Galassi, J. P., Schanberg, R., \& Ware, W. B. (1992). The Patient Reactions Assessment: A brief measure of the quality of the patient-provider medical relationship. Psychological Assessment, 4 (3), 346.

[23] Fair, C. D., \& Morrison, T. E. (2012). The relationship between prenatal control, expectations, experienced control, and birth satisfaction among primiparous women. Midwifery, $28(1), 39-44$. 
[24] Pantouvakis, A. (2010). The relative importance of service features in explaining.

[25] Harvey, S., Rach, D., Stainton, M. C., Jarrell, J., \& Brant, R. (2002). Evaluation of satisfaction with midwifery care. Midwifery, 18 (4), 260-267.

[26] Jafari, E., Mohebbi, P., \& Mazloomzadeh, S. (2017). Factors related to women's childbirth satisfaction in physiologic and routine childbirth groups. Iranian journal of nursing and midwifery research, 22 (3), 219.

[27] Jackson, J. L., Chamberlin, J., \& Kroenke, K. (2001). Predictors of patient satisfaction. Social science \& medicine, 52 (4), 609-620. 